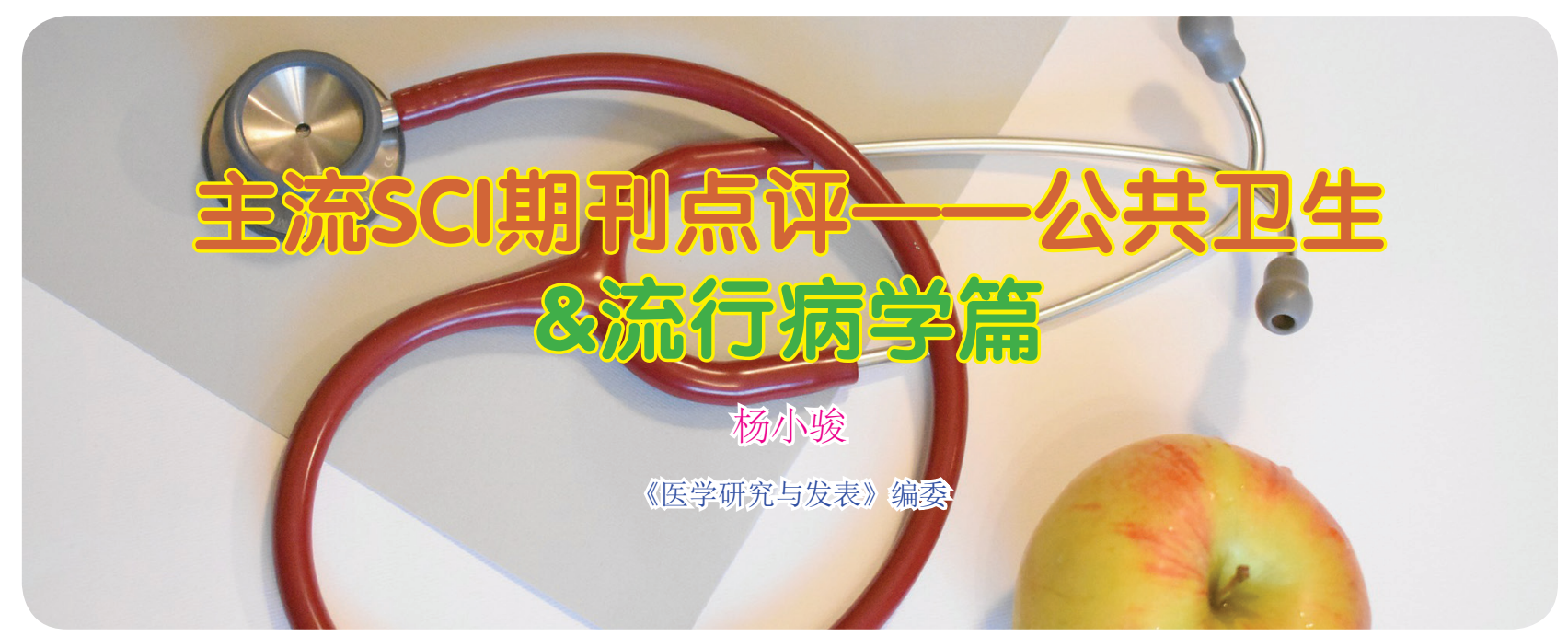

上篇我们主要介绍了公共卫生和流行病学领域 的几本顶级刊物, 对于这些刊物, 病理样本的收集 是最重要的因素。然而这样的资源对于基层的小医 生来说, 时常是 “可望不可及” 的。在本篇中, 我 们重点介绍一些公共卫生和流行病学领域中 IF 较低 的期刊, 这些期刊对于稿件质量和样本数量要求 “友 善” 得多。

\section{American Journal of Public Health (IF2017=4.38)}

比起上篇介绍的公共卫生和流行病学 SCI 刊物 的 “四大金刚”, 本杂志投稿难度显然降低了很多。 作为公共卫生领域 2 区期刊, 虽然年发文量超过了 600 篇, 但是无论是国内学者在该刊发表文章数量, 还是关注的人数都还不多。我们根据该杂志近年来 持续上升的影响因子来推测, 在未来几年内该刊还 是很有希望突破 IF5 的。如果您的稿件质量不错, 投稿该杂志的性价比还是很高。

\section{Epidemiology and Infection (IF2017=2.044)}

作为 IF3 以下的杂志, 比起 American Journal of Public health来说, 投稿难度又要低一个台阶。 在这个档次的杂志上, 即使 meta 分析类的文章, 拒 稿的可能性也比较小, 而分数对于职称晋升或者研 究生毕业来说也是绰绰有余。根据 IF 的趋势, 我们
推测未来几年冲到 3 分的可能性比较小。另外据说 该杂志的审稿速度较慢, 常常因为找不到审稿人而 拖很久, 所以着急毕业的同学们慎投。

\section{European Journal of Public Health (IF2017=2.782)}

比起 American Journal of Public health来 说, 欧洲公共卫生领域的 SCI 期刊显然是有些落后了。这 本杂志与 Epidemiology and Infection 的收稿质量、发 文数量、以及影响因子都相对接近。唯一有点不同的 是, 该杂志比上一个还要冷门, 更少有中国人投稿。 同时作为公共卫生和流行病学期刊的通病, 审稿人比 较难找且效率很低, 导致审稿和发表周期很长。

\section{BMC Public Health (IF2017=2.42)}

最后, 我们隆重 “推荐'BMC Public Health这 本杂志, 作为 $\mathrm{BMC}$ 旗下的杂志之一, 该刊年发文量 超过了 1000 篇, 影响因子跟上面两本杂志也差不多。 该杂志对于投稿文章的类型没有特别的限制, 从公 共卫生的基础研究到应用研究, 以及 meta 分析, 只 要结论明确, 基本都有可能被修回。然而还是有公 共卫生相关 SCI 期刊的通病, 就是审稿和发表周期 较慢, 通常都要经历半年以上的时间。另外, $\mathrm{BMC}$ 的杂志都属于开源刊物, 版面费收费不菲, 投稿时 需注意。 